\title{
Morfología urbana del Núcleo Histórico de Bellavista. Estudio de casos: Jirón Bolognesi y Plaza Isabel La Católica, 1949, 2019 $^{1}$
}

\author{
Urban morphology of the Historic Center of Bellavista. Case studies: \\ Bolognesi Street and Isabel La Catolica Square, 1949, 2019
}

\author{
María Patricia, Malpartida Pacaya \\ José Carlos , Hayakawa Casas² \\ ${ }^{1}$ y 2 Universidad Nacional de Ingeniería, Lima, Perú, Grupo de \\ investigación en patrimonio cultural Yuyai \\ 1patty.malpartida16@gmail.com / https://orcid.org/0000-0003-0297-1401 \\ 2jhayakawac@uni.edu.pe / https://orcid.org/0000-0003-3480-2151 \\ Recibido el 22 de abril de 2021, aprobado el 23 de diciembre de 2021
}

\begin{abstract}
RESUMEN | Poco se sabe del verdadero origen de Bellavista, distrito que nace en 1746 tras la catástrofe que terminó por destruir no solo a la Lima colonial, sino también al antiguo Callao amurallado. Fundada por el Virrey Manso de Velasco para convertirse en el Nuevo Puerto del Callao y cuyo diseño fue encomendado al ingeniero Luis Godín, el mismo que se encargó de diseñar la famosa Fortaleza del Real Felipe.

A pesar del gran valor histórico que posee, Bellavista solo tiene una declaración: la fachada del Estadio Telmo Carbajo. Lamentablemente es poco lo que se ha investigado de las edificaciones antiguas en este distrito. Por ello, el presente artículo tiene como finalidad presentar los estudios urbanos que muestran los cambios en la morfología urbana durante un periodo de 70 años en 1949 y 2019 enfocados en los ambientes urbanos monumentales: La Plaza Isabel La Católica y el Jirón Bolognesi, con la intención que dicho valor urbano-patrimonial permita obtener una declaratoria como bien integrante del Patrimonio Cultural de la Nación en su condición de Zona Monumental.
\end{abstract}

PALABRAS CLAVE | Zona Monumental de Bellavista-Callao, Plaza Isabel La Católica, Jirón Bolognesi, morfología urbana, 1949, 2019

\footnotetext{
1 Este artículo se basa en el trabajo de campo, en la investigación titulada "La evaluación urbana y arquitectónica del Casco Histórico de Bellavista para la declaración de Monumentos”, realizada durante el 2016 en el Taller de Investigación en Historia de la Arquitectura (TIHIS I, TIHIS II) -bajo la responsabilidad del Prof. MSc. Arq. José Beingolea Del Carpio- y del trabajo final del titulado "Nueva vista. Redescubre Bellavista" realizada durante el 2019-1 en el curso Taller de Centros Históricos -bajo la responsabilidad del Prof. Dr. José Hayakawa Casas- de la Facultad de Arquitectura, Urbanismo y Artes de la Universidad Nacional de Ingeniería (UNI).
} 


\begin{abstract}
Very little is known about the true origin of Bellavista, a district that was created in 1746 after the catastrophe that ended up destroying not only colonial Lima, but also the old city of Callao. Founded by the Viceroy Manso de Velasco to become the New Port of Callao and whose design was entrusted to the engineer Luis Godín, the same one who was in charge of designing the famous Real Felipe Fortress.
\end{abstract}

Despite its great historical value, Bellavista has only one statement: the facade of the Telmo Carbajo Stadium. Unfortunately little has been investigated about the old buildings in this district. Therefore, this article aims to present urban studies that show changes in urban morphology during a period of 70 years in 1949 and 2019 focused on monumental urban environments: Isabel La Católica Square and Bolognesi Street, with the intention that said urban-patrimonial value allows obtaining a declaration as an integral good of the Cultural Patrimony of the Nation in its condition of Monumental Zone.

KEYWORD | Monumental Zone of Bellavista-Callao, Isabel La Católica Square, Bolognesi Street, urban morphology, 1949, 2019

\title{
1. Introducción
}

Bellavista, o también llamada actualmente como la "ciudad jardín" del Callao, posee una historia que se remonta a los tiempos del Virreinato en el Perú, que nace tras una de las más trágicas catástrofes que el país ha atravesado, para convertirse en el nuevo Primer Puerto de la nación. Sin embargo, es una historia que pocos la conocen y que, lamentablemente, por aquella razón, se empiezan a ver los frutos del desconocimiento.

El presente artículo se basa en la investigación realizada por la autora en la revista Devenir $\mathrm{N}^{\circ}$ 13 bajo el nombre de "el Núcleo Histórico de Bellavista como zona monumental: análisis urbanoarquitectónico", el cual busca evaluar desde el aspecto urbano y arquitectónico el Núcleo Histórico de Bellavista encontrando los valores que posee con el fin que pueda ser entregado a las autoridades pertinentes y pueda servir como base y referencia para una posible declaración de monumentos.

Esta investigación intenta revelar aquellos estudios urbanos y arquitectónicos que demuestran la evolución de la Zona Urbana Monumental propuesta para el Núcleo Histórico de Bellavista en los últimos 70 años, con el fin que pueda servir de referencia para que se den acciones por parte de las entidades peruanas y poner en valor la zona histórica del distrito y frenar, en lo posible, este penoso proceso de degradación y de destrucción de su centro donde ya se ha demolido uno de sus más importantes hitos, el antiguo cine de Bellavista para dar paso a construir, nuevamente, un edificio multifamiliar. Por ello, para el análisis se enfoca en dos de sus ambientes urbanos monumentales más representativos y que cuentan con importantes características y valores que pueden hacer merecedora su posible declaración, los casos de: tramo del Jr. Bolognesi (desde la cuadra 01 hasta la cuadra 05) y la plaza Isabel La Católica, tomando como referencia las primeras aproximaciones de delimitación del Nuevo Centro Histórico de Bellavista y la lista de inventario realizada en el año 2016 en la primera investigación publicada sobre esta zona del distrito. 


\section{Metodología}

La metodología es cualitativa de enfoque histórico en virtud a que se orienta al análisis del objeto de estudio desde la interpretación de fenómenos sociales en sus diferentes etapas y cómo influyen en el objeto. Ante ello, para la realización de esta investigación, se contó con documentación de carácter gráfico respecto al diseño original del Núcleo Histórico de Bellavista. Dicha documentación está conformada por planos, fotografías, grabados, entre otros. Especialmente, se consideraron, como referencia, los primeros estudios exploratorios desarrollados en el artículo de Malpartida (2020), debido a que en dicho estudio se identifican, a través de tres matrices de clasificación categorizadas por las épocas Republicana, de Transición y Moderna, la relación de las edificaciones que como conjunto podrían cumplir con los requisitos para ser declarados ambientes urbanos monumentales.

A través de esta lista de edificaciones, se realizó un registro fotográfico de las viviendas que se encuentran en las calles circundantes a la Plaza Isabel La Católica y al Jirón Bolognesi, los cuales son los ambientes urbanos en los que el presente artículo se enfoca, permitiéndonos así poder conocer el estado actual de las zonas mencionadas.

Asimismo, para poder identificar los cambios en la morfología urbana de la posible zona monumental de Bellavista, se tomó como base la información registrada sobre el propuesto Núcleo Histórico de Bellavista (ver figura 01) y otra más detallada de ambos casos de estudio -Plaza Isabel La Católica, Jirón Bolognesi- referidas a 1949 en contraste con las de 2019, los cuales son de elaboración propia y pudieron realizarse gracias a registros fotográficos propios y a la revisión detallada de herramientas como Google Earth y Google Street View. Las fuentes y técnicas se componen por gráficos elaborados a partir de planimetría de dicho núcleo histórico, vistas aéreas y fotografías de los distintos periodos edificados (ver figura 02).

Por otra parte, para delimitar el área de estudio, se tomó como referencia el área diseñada por Luis Godín en 1747, el cual constaba originalmente de 25 manzanas, y cómo éste se ha ido transformando hasta el año 2019. Cabe destacar que al no haber mayor información actualizada, los planos de los procesos de transformación son de elaboración propia, además de que la parte final de este estudio se desarrolló en plena pandemia por Covid-19, merced a cuyas restricciones de desplazamiento se usaron videoconferencias para coordinar las labores y afinar la pesquisa.

Figura 1. Planos para la propuesta de delimitación del Centro Histórico de Bellavista
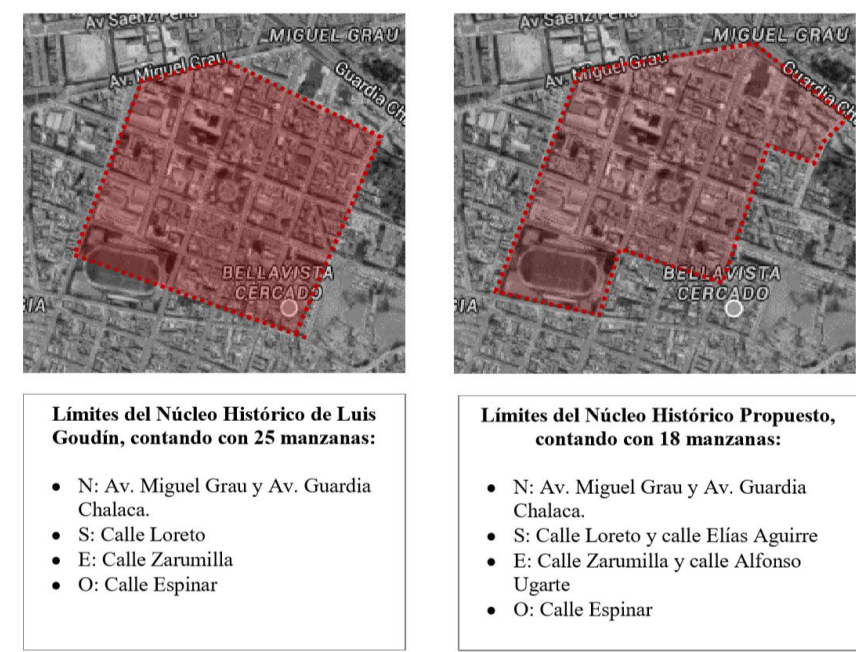

$$
\begin{aligned}
& \text { Limites del Núcleo Histórico Propuesto, } \\
& \text { contando con } 18 \text { manzanas: } \\
& \text { - N: Av. Miguel Grau y Av. Guardia } \\
& \text { Chalaca. } \\
& \text { - S: Calle Loreto y calle Elías Aguirre } \\
& \text { - E: Calle Zarumilla y calle Alfonso } \\
& \text { Ugarte } \\
& \text { - O: Calle Espinar }
\end{aligned}
$$

Nota. El Núcleo Histórico de Bellavista como Zona Monumental. Tomado del Análisis Urbano-Arquitectónico, Devenir, 7(13), 2020, p.49 
Figura 2. Fotografías de viviendan las épocas y tipos arquitectónicos que se pueden encontrar en el Núcleo Histórico de Bellavista

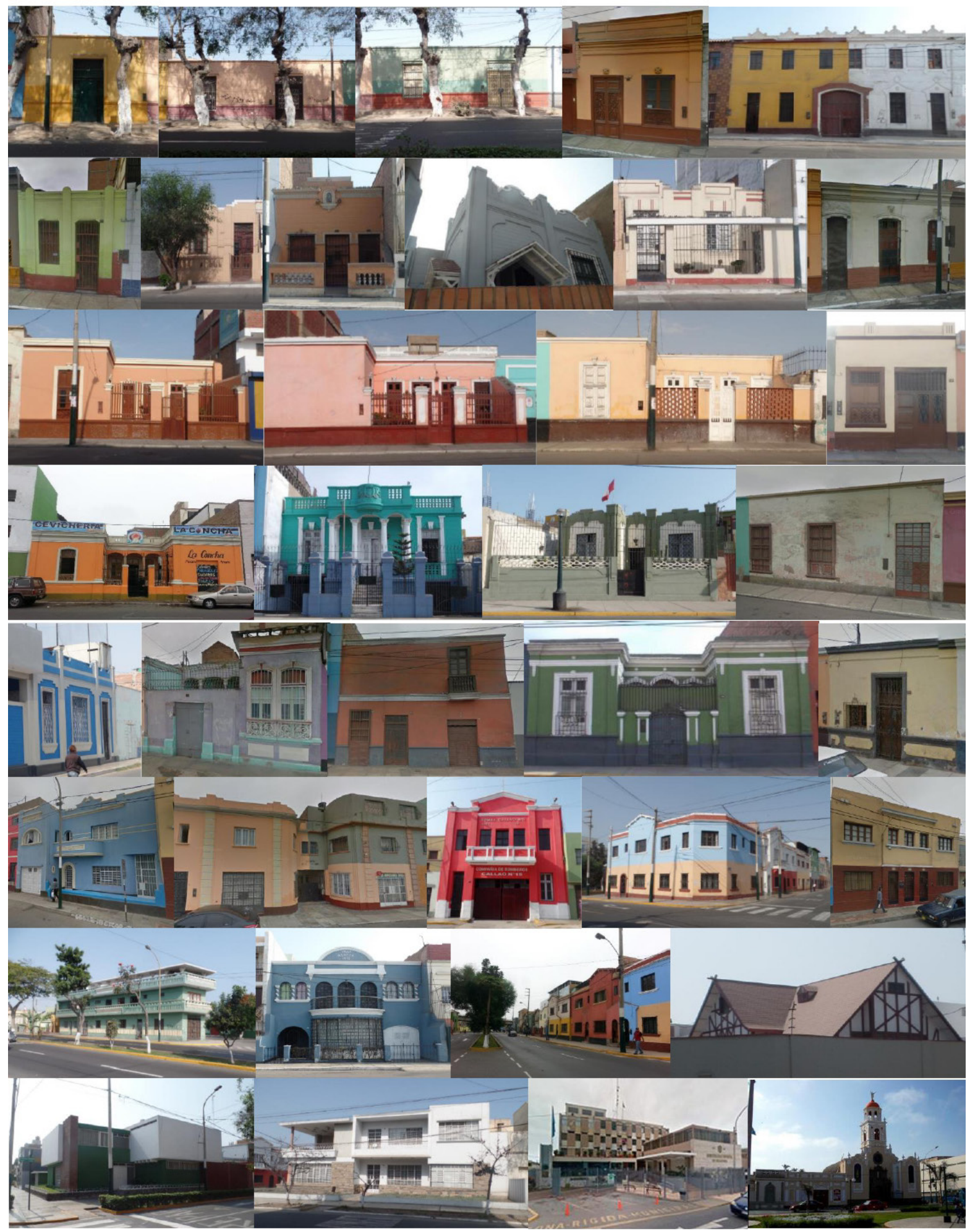

Nota. Tomado del Archivo fotográfico de Patricia Malpartida, 2016 


\section{Marco Teórico}

\section{Inventario UNI FORD}

El Inventario de Patrimonio Edificado más completo sobre la ciudad de Lima fue el Inventario del Patrimonio Monumental Inmueble - Lima: Valles de Chillón, Rímac y Lurín, realizado gracias al convenio entre la Facultad de Arquitectura, Urbanismo y Artes de la Universidad Nacional de Ingeniería y la Fundación FORD. Ésta ha sido una fuente consultada recurrentemente no sólo en lo informativo sino en lo metodológico porque su proceso de registro monumental ha sido considerado en la elaboración de la ficha respectiva.

Este inventario organiza el Patrimonio Monumental Inmueble en 4 épocas: Prehispánica (424 Monumentos), Virreinal (215 Monumentos), Republicana (239 Monumentos) y Contemporánea (183 Monumentos). El número total de monumentos considerados en el Inventario es de 1,061 en Lima.

- En este inventario, el proceso de relevamiento de información tuvo las siguientes etapas:

- Elaboración de una ficha estándar, que posee la suficiente flexibilidad y versatilidad para responder adecuadamente a contextos disímiles y que brinde información sobre los aspectos esenciales como ubicación, características, conservación e información gráfica.

- Elaboración de un listado previo de monumentos que permita obtener una aproximación al universo monumental investigado.

- Búsqueda de fuentes de información inéditas y conocidas que permitan identificar más certeramente al monumento.

- Recolección y relevamiento de datos.

- Llenado de fichas estándar.

- El paso final fue el procesamiento informático de datos (Hayakawa, 2001, pág. 143).

Cada monumento está presentado con una ficha que incluye:

- Identificación: Código del monumento, existencia actual, tipo genérico, tipo específico, Nombre del monumento, ubicación geográfica, ubicación política, datos cartográficos y fotográficos, y accesibilidad.

- Descripción del monumento: Área del terreno, área construida, área techada, filiación cultural, filiación cronológica, descripción, mobiliario y/o elementos.

- Datos históricos: Autor(es), comitente, etapas de construcción (años), intervenciones, tipos de intervenciones y años, bibliografía e inventario.

- Datos técnicos: Estado de conservación, sistema estructural, materiales predominantes, instalaciones, amenaza de destrucción, uso actual, tugurizado, 56 propietarios, saneamiento legal, declarado monumento, dispositivo legal, fecha dispositivo.

- Observaciones.

- Otros: Ejecución, revisión, visación y fecha. 
Asimismo, se incluye una foto del Monumento, un plano de ubicación, y planta de distribución. Es importante señalar que "la selección de los edificios, ambientes, conjuntos, etc. estuvo supeditada a distintos criterios. Cabe señalar, sin embargo, que se han incluido indistintamente Monumentos ya declarados en la Legislación como sujetos de preservación y otros que se propone como tales" (Fundación Ford - Universidad Nacional de Ingeniería, 1988).

Por otra parte, se ha considerado como referencia teórica gran parte de las aproximaciones intelectuales de Alejandra Sgroi (Sgroi, 2009) relativas a la Morfología Urbana y en especial sobre las categorías de la Forma Urbana, tales como:

\section{Traza}

Organización espacial básica determinada por la red vial (calles) y los lotes que delimita. Puede ser:

- Cuadricular: Crecimiento simétrico a partir de dameros perfectos.

- Irregular: Se presenta cuando se rebasa la forma original con crecimientos asimétricos que amenazan o desvirtúan su orden básico.

- Irregular Radial o Concéntrica: utilizado cuando se organiza la ciudad en torno a un punto central, a partir del cual, se proyectan las calles que la comunican con el exterior o periferia.

- Barroca: Derivada del damero pero enriquecida por la tradición de los trazados ideales del urbanismo barroco que genera plazuelas, rotondas y otros elementos que rompen con la uniformidad de la cuadrícula. (Malpartida, El Núcleo Histórico de Bellavista como Zona Monumental: Análisis Urbano-Arquitectónico, 2020, pág. 45)

\section{Manzana}

Es el espacio urbano delimitado por espacios abiertos (calles, plazas u otros) en todos sus lados y que está destinado para el parcelamiento. Dependiendo de su forma pueden ser:

- Cuadrada: Reproduce análogamente la manzana típica de las ciudades de la conquista.

- Rectangular: En distintas dimensiones, brinda una mejor proporción en los lotes y en algunos casos racionalidad en la configuración de la red circulatoria, aunque en otros casos responde a una cuestión formal.

- Triangular: Originado por la irrupción de diagonales sobre la trama reticulada. También origina manzanas trapezoidales con dificultades en el fraccionamiento parcelario. (Malpartida, El Núcleo Histórico de Bellavista como Zona Monumental: Análisis UrbanoArquitectónico, 2020, pág. 45).

\section{Parcela}

Subdivisión de terrenos en nuevas parcelas independientes. Existen las siguientes variantes:

- Tipo X: Modelo universal de parcelamiento de la manzana cuadrada. Adoptado a fin de lograr la mayor cantidad de fracciones con acceso directo a la vía pública.

- Tipo H.- Aplicado en manzanas cuadradas pero especialmente en rectangulares con el fin de lograr lotes no muy dispares. 
- Tipo Y.- La manzana triangular tiene la dificultad de no poder ser parcelada racionalmente. De ella surgen lotes triangulares, cuadriláteros, de todo tipo y polígonos más complicados.

- Tipo Curvilíneo.- Se trata de una manzana irregular o curvilínea que produce un tipo diferente de parcelación, donde se dificulta su mesura y la regularidad de sus lotes. (Malpartida, El Núcleo Histórico de Bellavista como Zona Monumental: Análisis Urbano-Arquitectónico, 2020, pág. 45).

\section{Textura}

Es la estructura que define las formas de la relación entre llenos y vacíos, entendida como la interacción de volúmenes edificados y espacios abiertos. Ello, permite percibir la mayor o menor compacidad y el suelo libre. La textura eventualmente podría revelar densidades, ya que se trata esencialmente de la compactación de la superficie pero no considera el uso edilicio. Tenemos 2 variantes:

- Cerrada (- vacíos | + 1lenos): La manzana alcanza su completamiento y los huecos de los lotes son sustituidos por construcciones, dando como resultado una trama cerrada que solo respira a través de la red de calles.

- Abierta (+ vacíos | - llenos): Se da por un parcelamiento holgado y bajo porcentaje edificado, o por encontrarse el tejido urbano en un estado intermedio en el proceso de compactación. (Malpartida, El Núcleo Histórico de Bellavista como Zona Monumental: Análisis UrbanoArquitectónico, 2020, pág. 45).

\section{Marco Contextual}

Bellavista es uno de los siete distritos que conforman la Provincia Constitucional del Callao en el Perú. Es el segundo distrito con mayor antigüedad de la provincia chalaca y uno de los más antiguos de Lima. En cuanto a su elevación distrital "se dio el 6 de octubre de 1915 mediante la ley $\mathrm{N}^{\circ}$ 2141, la cual también creó el distrito de La Punta" (Municipalidad Distrital de Bellavista, 2019-2022).

Es un distrito residencial consolidado con una población de 74.851 habitantes, según el último Censo realizado en el Perú en octubre del año 2017, y uno de los pocos en la región en poseer una forma regular, pues se presenta como un rectángulo cuya base inferior está alineada con el eje de la Av. Venezuela y su prolongación natural la Av. José Gálvez. Al norte, la base superior alineada con la Av. Óscar R. Benavides (antes Av. Colonial) y su prolongación la Av. Sáenz Peña. Por el este, se extiende hasta el Hospital Centro Médico Naval «Santiago Távara» y su perímetro oeste de la Universidad Nacional Mayor de San Marcos, el cual da inicio a la Provincia de Lima (ver figura $03)$.

En cuanto a su emplazamiento, "Por su ubicación privilegiada que permite ver la bahía desde sus calles, recibió el nombre de Bellavista" (Malpartida, El Núcleo Histórico de Bellavista como Zona Monumental: Análisis Urbano-Arquitectónico, 2020, pág. 44). Al establecerse sobre un terreno a 17 m.s.n.m., el paisaje terminó siendo un valor agregado que posee su Núcleo Histórico, puesto que peatonalmente se siente la imposición del lugar con respecto a la bahía, y este tipo de paisaje es único en el Callao (ver figura 04), mismo que se observa en el Jr. Bolognesi, desde su dirección Norte-Sur y con cercanía a la plaza Isabel La Católica, donde se contempla parte del paisaje marino. 
Figura 3. Plano de localización de Bellavista

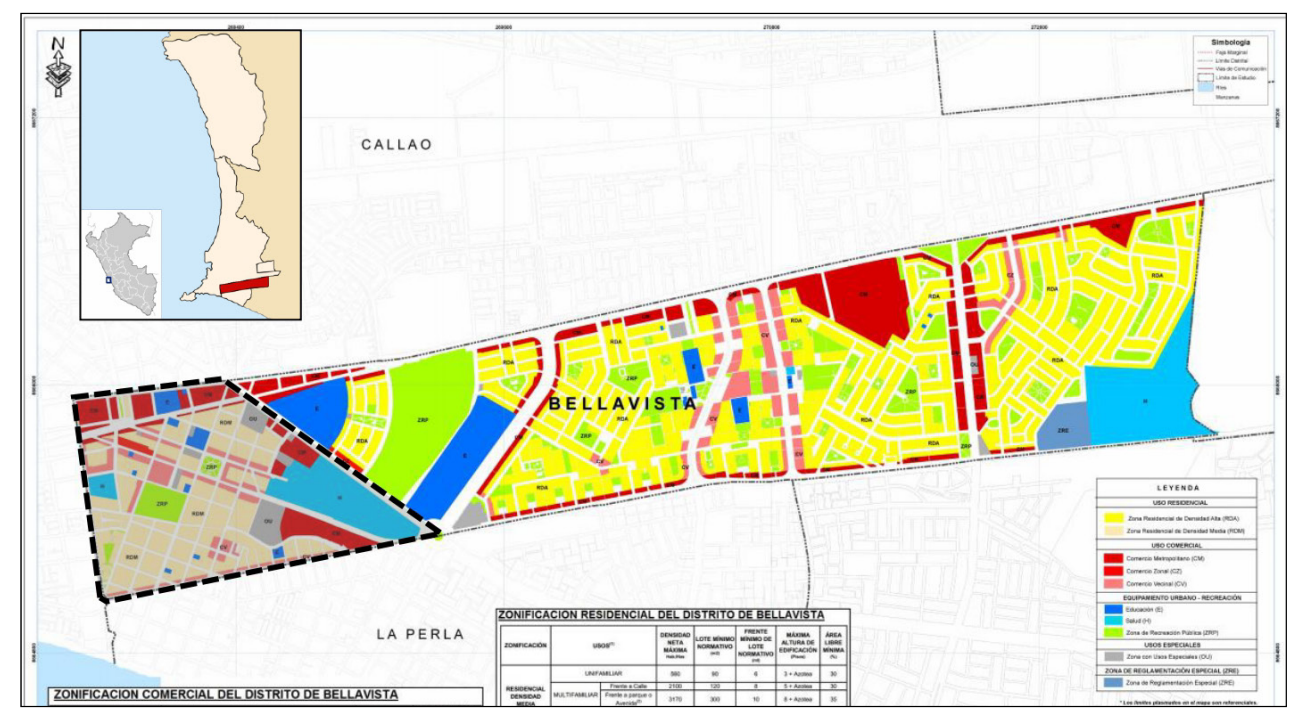

Nota. Elaboración propia sobe la base del plano del Equipo de Actualización del Plan de Desarrollo Urbano 2018 de la Municipalidad Provincial del Callao (Municipalidad Provincial del Callao, 2018), 2021

Figura 4. Aerofotografía donde se observa el emplazamiento de Bellavista

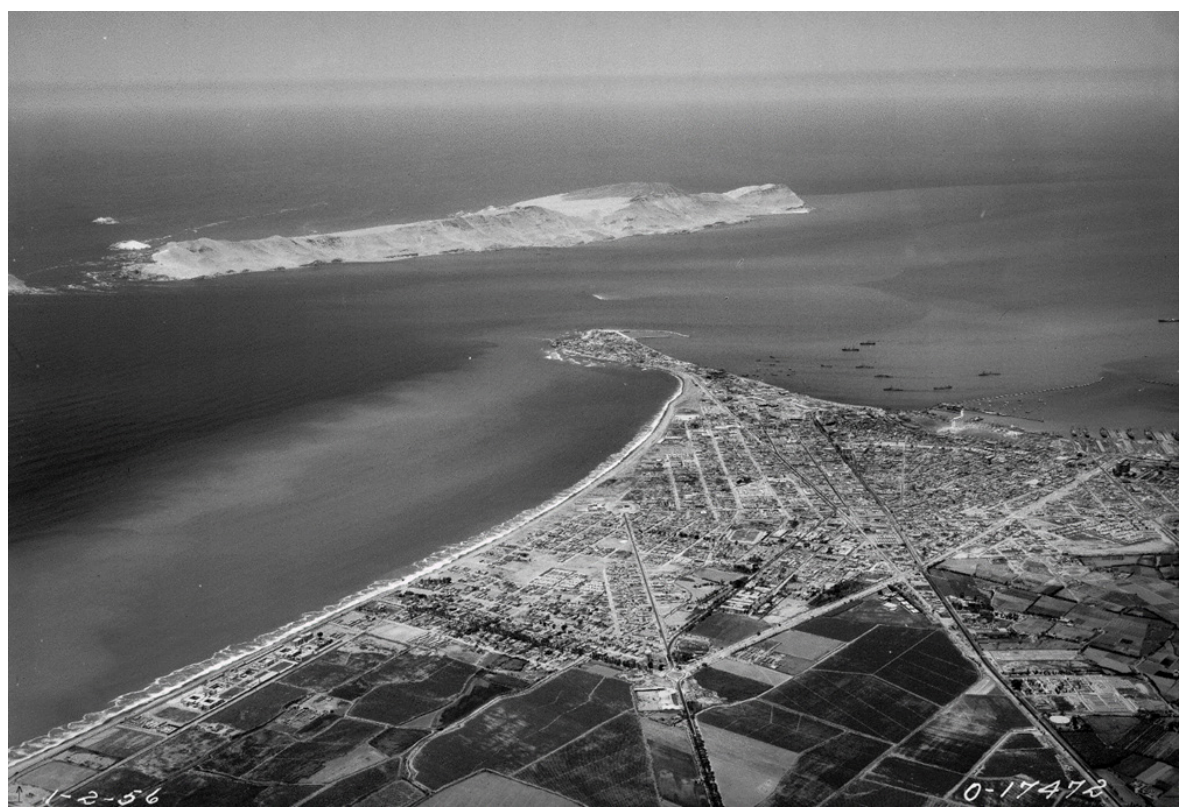

Nota. Tomado del archivo del Servicio Aerofotográfico Nacional, 1956

\section{Marco Histórico}

\section{Las etapas de su Historia Urbana}

De acuerdo con la información recopilada y la observación crítica basada en la vivencia de la autora como habitante del Núcleo Histórico de Bellavista, se pueden determinar 5 etapas que marcaron y empiezan a resaltar en la historia urbana de Bellavista (ver figura 05). 
Figura 5. Línea de tiempo de las etapas de la historia urbana de Bellavista

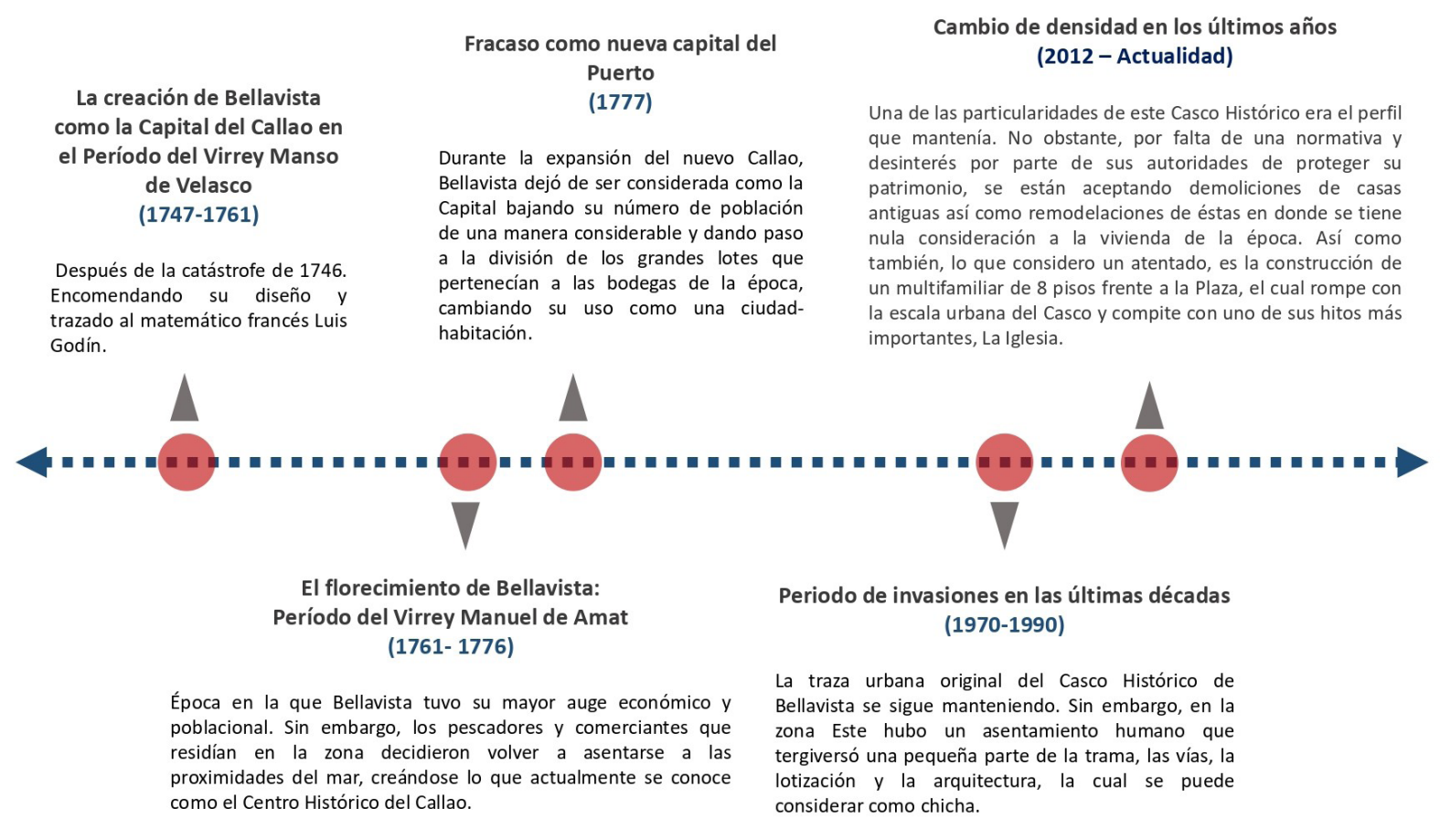

Nota. Tomado La evaluación urbana y arquitectónica del Casco Histórico de Bellavista para la Declaración de Monumentos, 2016.

\section{Los Periodos de su Arquitectura}

En cuanto a la arquitectura del Centro Histórico de Bellavista, a pesar que “... de la época Colonial no queda en pie ninguna construcción más que la Plaza Isabel La Católica, la arquitectura del Casco Histórico de Bellavista se desarrolla en 03 periodos: Republicano, época de Transición y Moderno" (Malpartida, 2016, pág. 89).

a) Época Colonial (1747 - 1820)

De esta época ya no existen construcciones arquitectónicas que la evidencien. Sin embargo, queda la plaza, cuyo trazado repitió algunos rasgos del urbanismo del siglo XVI de las ciudades hispanoamericanas "(...) un tipo nítidamente definido por su estructura física en cuadrícula, sin acentos ni contrastes y con un único elemento diferenciado al centro: la plaza central" (Ríos, 2014, pág. 43).

Por lo tanto, la traza tuvo las siguientes 03 principales características:

- Se adoptó una trama reticular y con perímetro poligonal.

- "Algunos trazados de este período reflejan preocupaciones de tipo forma lista y simbólico, destinadas a proyectar una imagen de la ciudad superior a su verdadera consistencia... responden a conceptos teóricos de defensa modernos”. (Mattos-Cárdenas, 2004, pág. 89) .

- La organización espacial a partir de una plaza regular central, “...espacio público principal y 
corazón de la urbe, el núcleo estructural básico desde donde se genera y articula la ciudad: la plaza mayor, centro geométrico, vital y simbólico" (Quevedo, 2016, pág. 13). En esta Plaza Mayor se ubicó la Iglesia Parroquial y demás edificios públicos.

b) Época Republicana (1821 - 1920)

De la época Republicana, quedan muy pocos ejemplares de viviendas rancho que queden en pie. En los jirones Grau, Bolognesi y Heros son las calles donde se encuentran las construcciones más resaltantes de este periodo, en donde la fachada es lo que, en su mayoría, evidencia que pertenecen a este periodo, debido a que en su estructura y distribución interna original han sido modificadas.

c) Época de Transición (1920-1950)

Dentro de la Época de Transición es donde encontramos más ejemplares y de donde se distingue su Núcleo Histórico. La mayor cantidad de viviendas unifamiliares y multifamiliares de este periodo se desarrollan en el estilo Art-Decó; además, existen algunas casas de estilo Buque y una construcción de estilo Pintoresquista y Exótico (Tudor) que actualmente pertenece a la Institución Educativa Particular "Panamericana", ubicada en el jirón Bolognesi. Cabe agregar, que dentro de esta época se encuentra también la actual Parroquia San José de Bellavista ubicada frente a la Plaza; otro ejemplar arquitectónico es el Cine de Bellavista, cuyo predio también se ubica frente a la Plaza y se remonta a la época Colonial, ya que en un inicio fue la Casa del Virrey, no obstante, ha sido demolida (ver figura 06).

d) Época Moderna (1940 - 2019)

Del periodo Moderno se encuentran distintos tipos arquitectónicos como viviendas unifamiliares, multifamiliares y el edificio de la Municipalidad. Cabe resaltar que, en los últimos tres años, se ha construido un multifamiliar frente a la Plaza que ha terminado por romper con el perfil urbano que caracteriza la zona.

\section{Resultados}

\section{Morfología Urbana}

\section{Traza}

De acuerdo con el Plano Catastral y el gráfico estadístico de 1949 versus el del 2019, se pueden determinar las siguientes características en la traza (ver figura 07):

- La traza se mantiene intacta en forma, superficie y orientación con respecto a la de 1949. Su superficie cuenta con un área de $87,900 \mathrm{~m} 2$, la cual se puede constatar que se mantiene en ambos años de estudio.

- La traza es cuadricular-ortogonal creando un damero y está orientada hacia el Nor-Este y Sur-Oeste. La traza está delimitada por las siguientes calles: por el Norte, con Av. Miguel Grau y Av. Guardia Chalaca; por el Sur, con el jirón Loreto y la calle Maranga; por el Este, con la calle Zarumilla; por el Oeste, con el jirón Comandante Espinar. Sin embargo, las dos vías diagonales en la zona Norte (Av. Buenos aires - Av. Guardia Chalaca) rompen con esta ortogonalidad. De igual manera, en el límite sur del área, la calle Maranga se muestra curvilínea tal y como era en la época Colonial (antiguo camino hacia el pueblo de La Magdalena). 


\section{Crquitectura +}

- Se observa que la traza se modifica en la zona Este debido a una invasión que creó un Pueblo Joven dentro del área de estudio generando discontinuidad en esta parte de la traza.

Figura 6. Aerofotografía de la propuesta de la Zona Monumental de Bellavista y su entorno urbano inmediato durante el año 1949

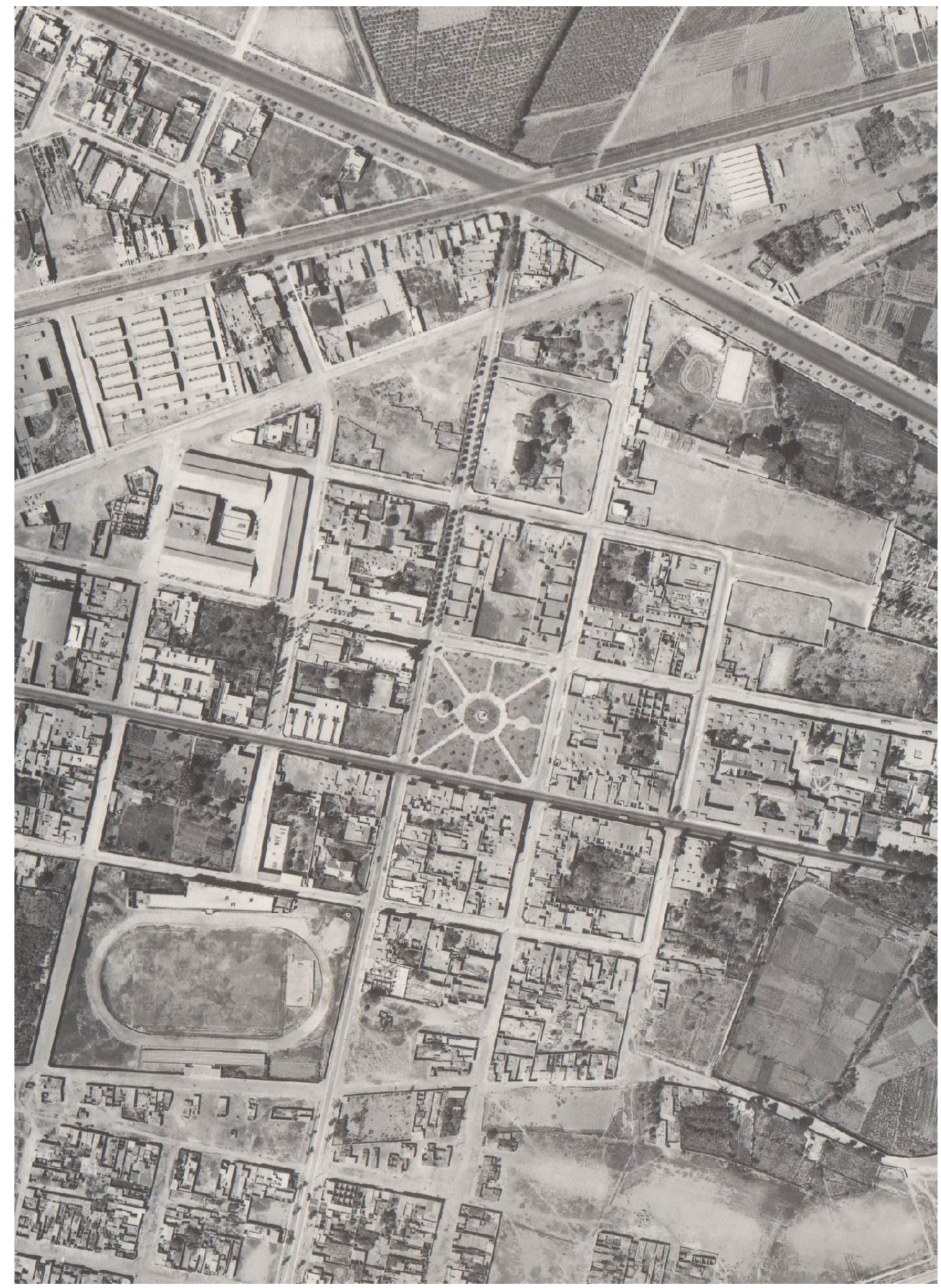

Nota. Tomado La evaluación urbana y arquitectónica del Casco Histórico de Bellavista para la Declaración de Monumentos, 2016. 
Figura 7. Comparación de planos del estudio de la traza del Núcleo Histórico de Bellavista en base al Plano Catastral de 1949 versus el del 2019
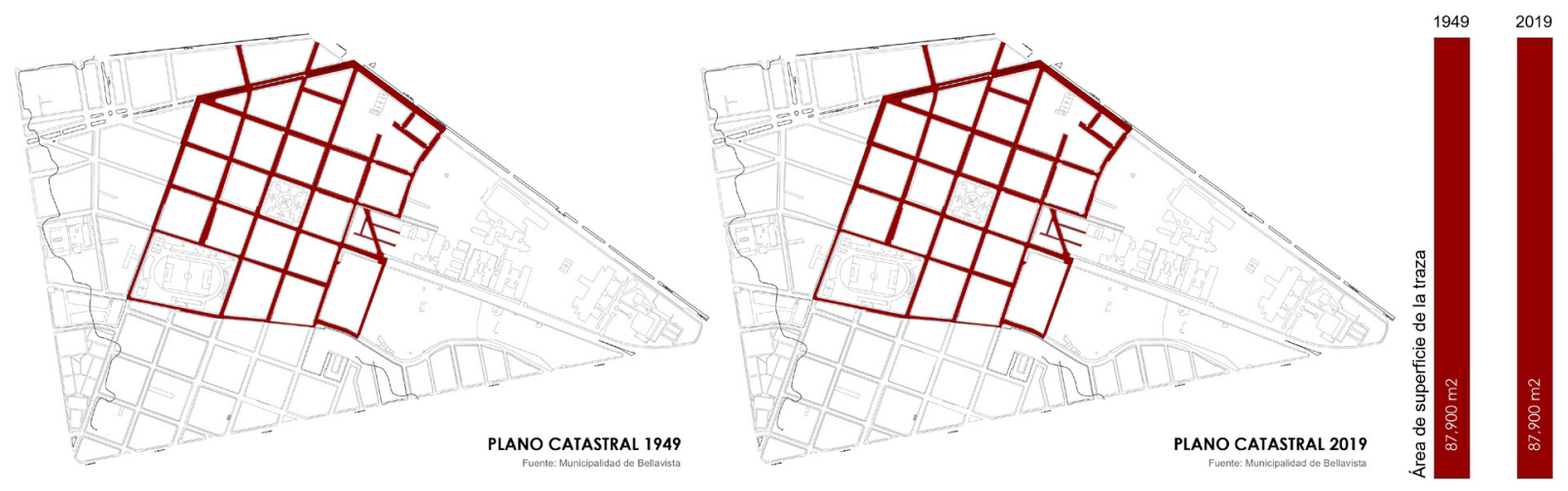

Nota. Elaboración propia, 2021

Se precisa otra discontinuidad en la zona S0 debido a la construcción del Estadio Telmo Carbajo. Asimismo ocurre en la zona NE por la construcción del Club de Tiro del Callao.

\section{Manzana}

Figura 8. Comparación de planos del estudio de manzanas del Núcleo Histórico de Bellavista en base al Plano Catastral de 1949 versus el del 2019

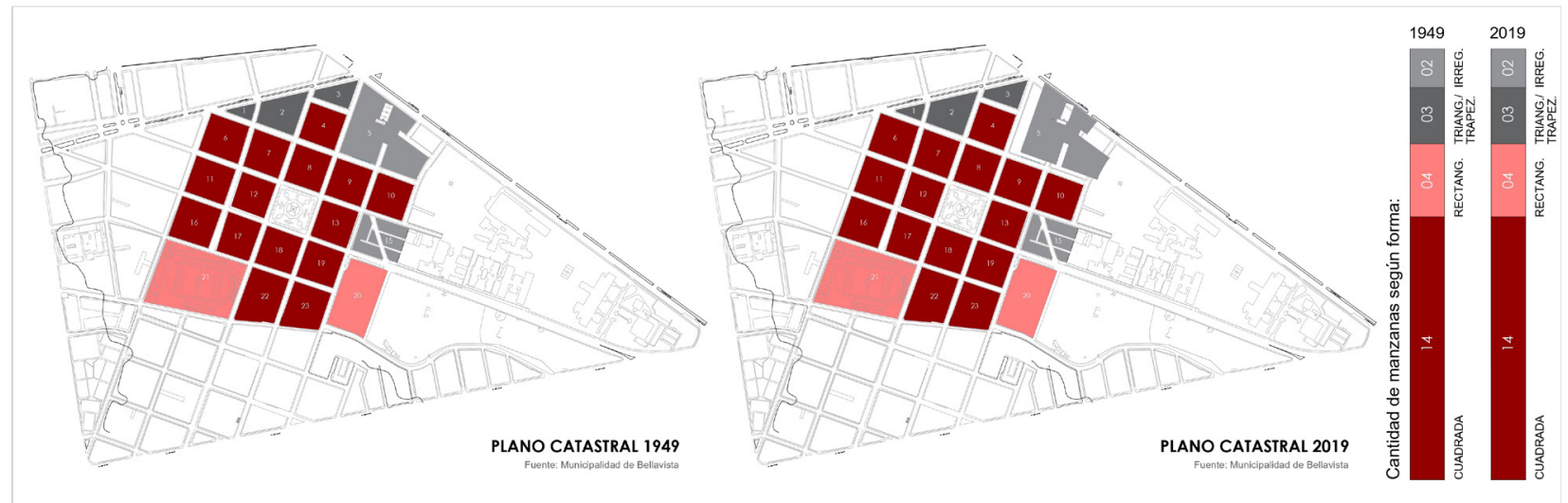

Nota. Elaboración propia, 2021

Conforme al Plano Catastral y el gráfico estadístico de 1949 versus el del 2019, de 23 manzanas en total, se identifican las mismas características que en 1949 (ver figura 08):

- Se detecta que 14 manzanas, las cuales equivalen al 61\%, son cuadradas con dimensiones aproximadas de 90 x 90 metros. Dichas manzanas son las siguientes: 4,6,7,8,9,10,11,12,13 ,14,16,17,18,19.

- Se determina que 04 manzanas, las cuales equivalen al 17\%, son rectangulares. 02 de ellas son producto de la unión de dos manzanas cuadradas. Dichas manzanas son las siguientes: $20,21,22,23$.

- Se identifica que 03 manzanas, las cuales equivalen al 13\%, son triangulares y trapezoidales. Dichas manzanas son las siguientes: 1, 2,3. 
- Se constata que 02 manzanas, las cuales equivalen al 9\%, son irregulares debido a la creación de nuevas vías (invasión), como la manzana $\mathrm{n}^{\circ} 15$ y por la unión dispareja de dos manzanas, como la manzana $n^{\circ} 5$.

\section{Parcelación}

Con base en el Plano Catastral y el gráfico estadístico de 1949 versus el del 2019, se puede Figura 9. Comparación de planos del estudio de la parcelación del Núcleo Histórico de Bellavista en base al Plano Catastral de 1949 versus el del 2019

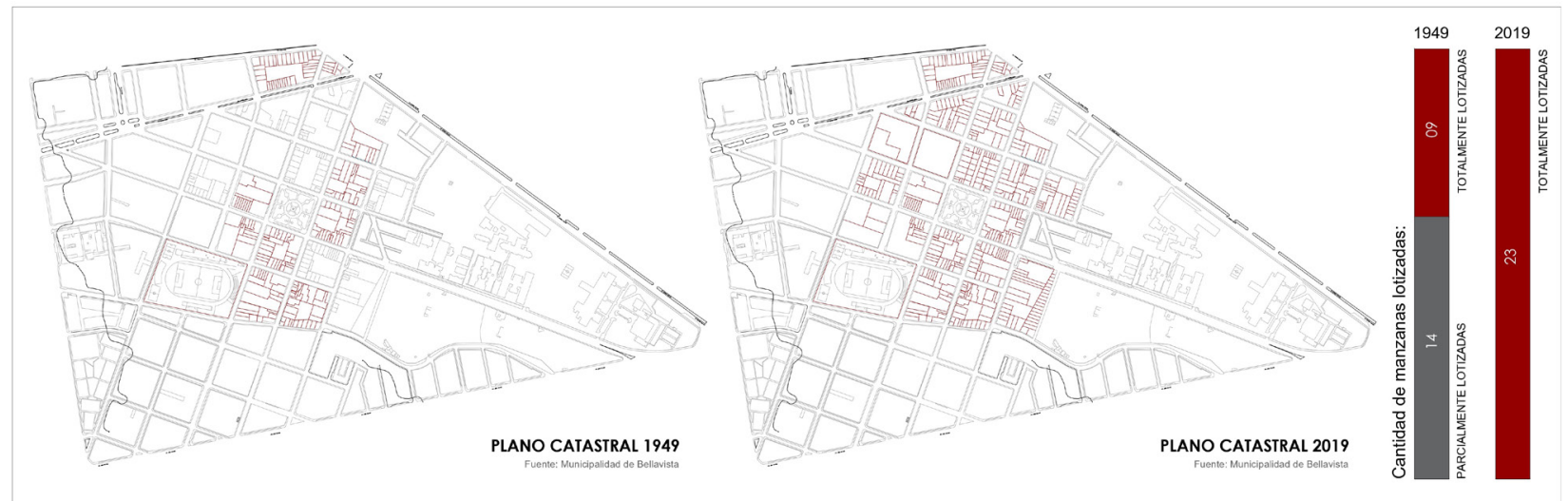

Nota. Elaboración propia, 2021

cotejar similitudes y diferencias en base a ambos años (ver figura 09):

- Se comprueba que, a comparación del año 1949, donde 14 manzanas era el número que correspondía a aquellas que se encontraban parcialmente consolidadas, lo cual equivale a un $61 \%$ del total, para el año 2019, las 23 manzanas, es decir, el 100\%, se encuentran ya lotizadas en su totalidad.

- Se determina que los lotes que podemos encontrar en el área de estudio son de forma regulares e irregulares.

- Es observable que los lotes están distorsionados con respecto al tipo «X», «H» e «Y», además que, en algunas manzanas, aún se pueden encontrar lotes de $135 \mathrm{~m} 2$ hasta lotes de $2500 \mathrm{~m} 2$. Es decir, se comprueba que no hay una lotización regular.

- Se precisa que, a comparación del año 1949, las manzanas que pertenecían a un dueño, finalmente fueron lotizadas en su totalidad y divididas entre otros propietarios.

- Se constata que hay 2 manzanas que mantienen las mismas características como en 1949, en donde los lotes están dispuestos de tal forma que se crean callejones quedando un amplio espacio central en la manzana.

\section{Textura}

De acuerdo con el Plano Catastral y el gráfico estadístico de 1949 versus el del 2019, en relación a la textura del área de estudio, se comprueba lo siguiente (ver figura 10):

- En 1949, se puede describir que su textura en general tiende a ser abierta, es decir, en 12 
manzanas predomina el vacío. Eso equivale a 52\% de las manzanas que tienen textura abierta, mientras que 11 manzanas, lo cual equivale al 46\% del total, se puede observar que presentan textura cerrada, es decir, no predomina el 1leno. Para el año 2019, estos porcentajes cambian.

- En 2019, se identifica que su textura en general tiende a ser cerrada, es decir, en 20 manzanas predomina el lleno. Eso equivale a $87 \%$ de las manzanas que tienen textura cerrada, mientras que 03 manzanas, lo cual equivale al 13\% del total, se determina que presentan textura abierta, es decir, no predomina el vacío.

- Para el año 1949, se precisa que de las 11 manzanas restantes en donde tiende a ser una textura cerrada, los espacios libres que se observan equivalen hasta un 30\% del área libre de la manzana. En el año 2019, se coteja que de las 12 manzanas que tendían a ser de textura abierta, ahora tienden a ser cerradas debido a la nueva parcelación y a la construcción de

Figura 10. Comparación de planos del estudio de la textura del Núcleo Histórico de Bellavista en base al Plano Catastral de 1949 versus el del 2019

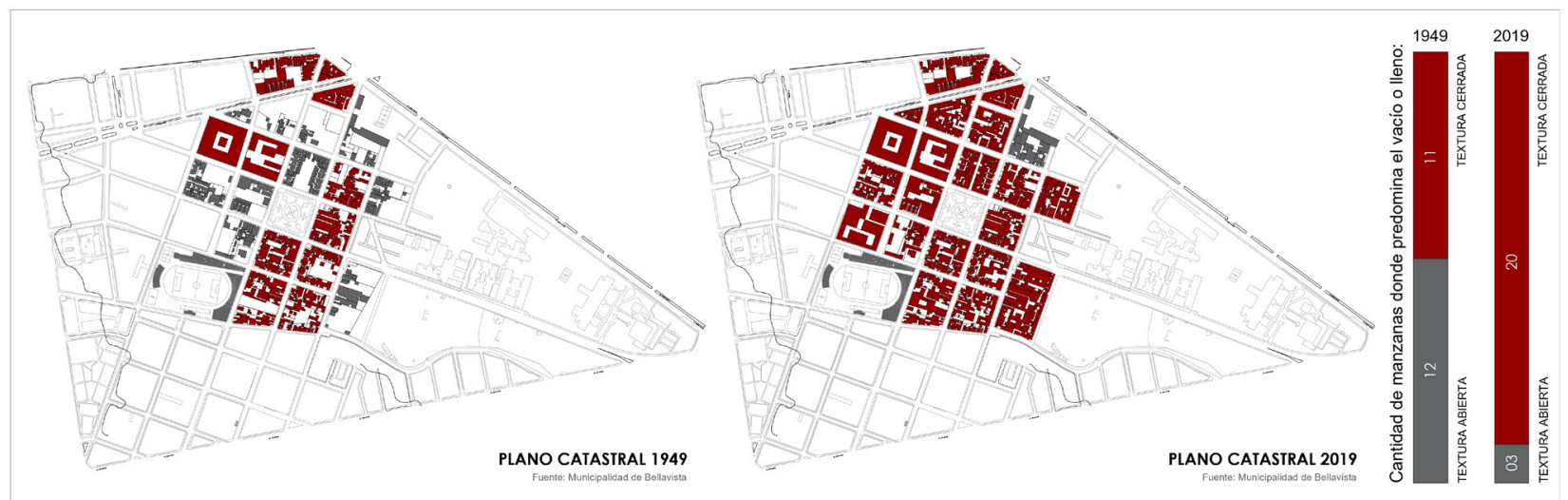

Nota. Elaboración propia, 2021

nuevas viviendas.

\section{Plaza Isabel La Católica}

Para el caso de la Plaza Isabel La Católica, en cuanto a la traza, en base al Plano Catastral y el gráfico estadístico de 1949 versus el del 2019, se identifican las siguientes características (ver figura 11):

- La traza se mantiene intacta en forma, superficie y orientación con respecto a la de 1949.

- Su superficie cuenta con un área de 29,660 m2, la cual se constata que se mantiene en ambos años de estudio.

- La traza es cuadricular-ortogonal orientada hacia Nor-Este y Sur-Oeste creando un damero delimitado por las siguientes calles: por el Norte, con jirón Nicolás de Piérola; por el Sur, con el jirón Elías Aguirre; por el Este, con el jirón Alfonso Ugarte; por el Oeste, con el jirón Víctor Fajardo.

- No es observable discontinuidad en su traza. 
Figura 11. Estudio de la morfología urbana de la Plaza Isabel La Católica, 1949, 2019

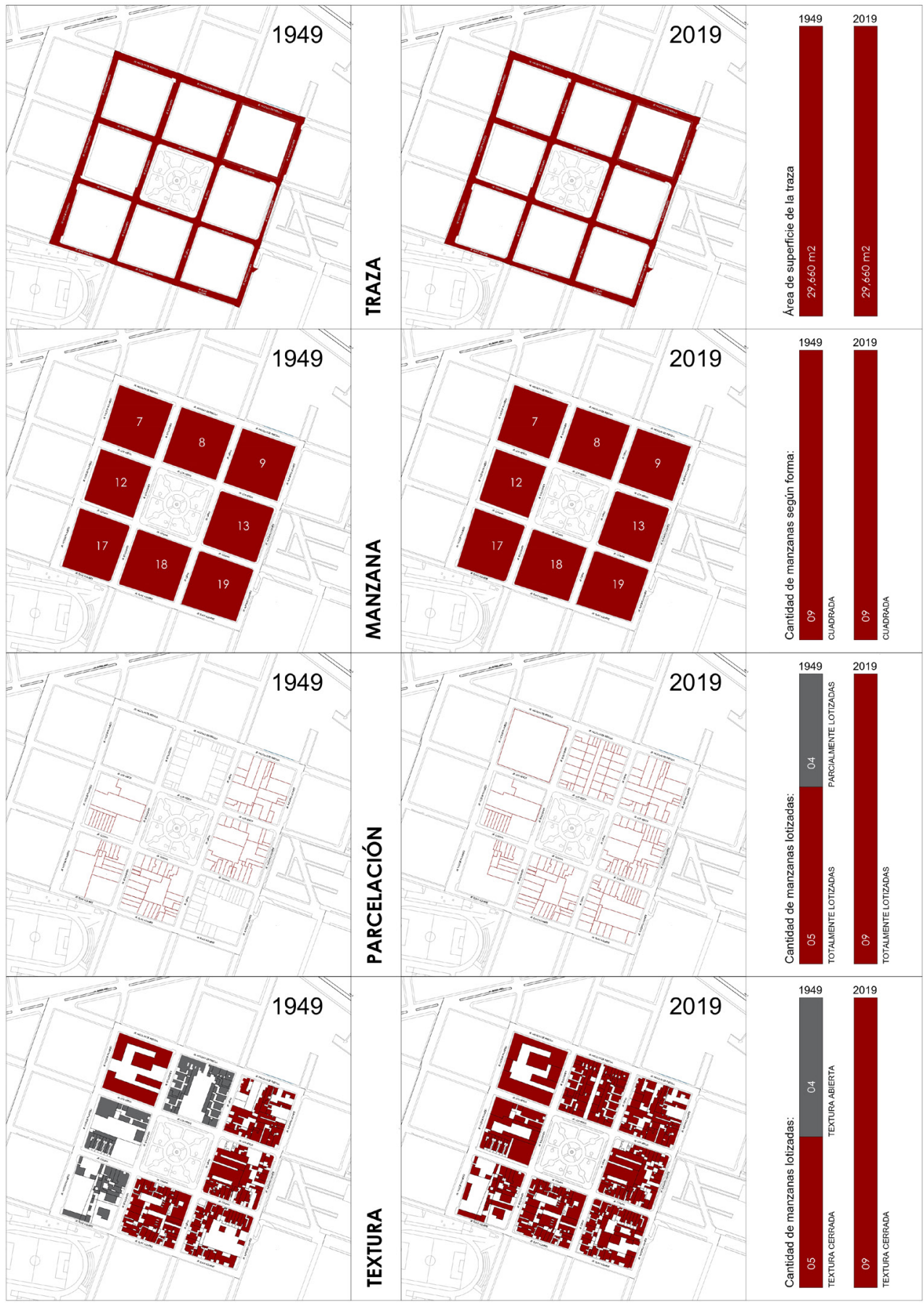

Nota. Elaboración propia, 2021 con base en: para el año 1949, de aerofotografía del Servicio Aerofotográfico Nacional; para el 2019, al trabajo de la Universidad Nacional de Ingeniería (Malpartida, La evaluación urbana y arquitectónica del Casco Histórico de Bellavista para la Declaración de Monumentos, 2016) y trabajo de campo

En relación a las manzanas, con base en el Plano Catastral y el gráfico estadístico de 1949 versus el del 2019, de 09 manzanas en total, se observan las mismas características que en 1949: 
- Queda constatado que de 09 manzanas, las cuales equivalen al 100\%, todas son cuadradas con dimensiones aproximadas de 90x90 metros. Dichas manzanas son las siguientes: 7, 8, $9,12,13,17,18,19$.

Referente a la parcelación, teniendo en cuenta el Plano Catastral y el gráfico estadístico de 1949 versus el del 2019, de 09 manzanas en total, se describen las siguientes características:

- En el año 1949, se precisa que 05 manzanas que rodean la plaza se encuentran totalmente lotizadas, mientras que 04 manzanas se encuentran parcialmente lotizadas.

- En el año 2019, se identifica que las 08 manzanas que rodean la plaza, incluyendo esta última, se encuentran ya totalmente lotizadas.

- Se observa que los lotes que se encuentran en el área de estudio son de forma regulares e irregulares.

- Es observable que los lotes están distorsionados con respecto al tipo «X», «H»e «Y», además que, en algunas manzanas, aún se enuentran lotes de $135 \mathrm{~m} 2$ hasta lotes de $2500 \mathrm{~m} 2$. Es decir, se comprueba que no hay una lotización regular.

Para la variable textura, de acuerdo con el Plano Catastral y el gráfico estadístico de 1949 versus el del 2019, de 09 manzanas en total, se cotejan las siguientes características:

- En 1949, se describe que su textura en general tiende a ser cerrada, es decir, en 05 manzanas predomina el lleno. Esto equivale a $56 \%$ del total de manzanas que tienen textura cerrada, mientras que 04 manzanas, lo cual equivale al 44\% del total, se observa que presentan textura abierta, es decir, no predomina el vacío. Para el año 2019, estos porcentajes cambian.

- En 2019, se identifica que su textura en general tiende a ser cerrada, pues el 100\% de ellas, es decir en las 09 manzanas, predomina el lleno.

La Plaza data de la época de la Colonia y se impone como el espacio público central del Núcleo Histórico de Bellavista el cual alberga los principales edificios del distrito, como la Parroquia San José, la Municipalidad y lo que fue un edificio emblemático en su época y en el Callao, el Cine de Bellavista, el cual infortunadamente ha sido demolido a fines del año 2019 para dar paso a un nuevo multifamiliar.

Se comprueba que en el caso de la Plaza Isabel La Católica, es el único ambiente urbano que queda en pie y que data de la época de la Colonia y que conserva su pileta original. Esta la Pileta Histórica de Bellavista se ubica al centro de la plaza y data del año de 1869 en conmemoración a la Guerra del Pacífico, la cual es bueno mencionar que se mandó a restaurar cerca al año 2013.

Asimismo, a través de esta plaza y la ubicación de sus edificios principales, es que se observa que el diseño urbano de la época: la traza es de diseño reticular con la plaza como centro y eje principal, mismos principios que se siguieron no solo para la Lima fundacional, sino también para diversas ciudades latinoamericanas. Se resalta también que la Plaza es el centro de reunión más representativa pues en él se desarrollan los eventos cívicos más importantes donde involucran no solo a los vecinos de la zona, sino también a los residentes de todo el distrito y a los centros educativos próximos. 
La Plaza, como se menciona anteriormente, alberga los edificios más importantes no solo del barrio sino también del distrito, como lo son la Municipalidad Distrital de Bellavista y la Parroquia San José.

\section{Jr. Bolognesi}

Para el caso del Jirón Bolognesi, en cuanto a la traza, con base en el Plano Catastral y el gráfico estadístico de 1949 versus el del 2019, se observan las siguientes características en la traza (ver figura 12):

- La traza se mantiene intacta en forma, superficie y orientación con respecto a la de 1949.

- La traza es ortogonal y está orientada hacia el Nor-Este y Sur-Oeste y comprende desde la calle 01 hasta la calle 05 del jirón Bolognesi.

- Su superficie cuenta con un área de $4,070 \mathrm{~m} 2$, la cual se constata que se mantiene en ambos años de estudio.

- No es observable discontinuidad en su traza.

Respecto a la variable de manzanas, acorde al Plano Catastral y el gráfico estadístico de 1949 versus el del 2019, de 09 manzanas en total, es observable las mismas características que en 1949:

- Se determina que 07 manzanas, las cuales equivalen al $78 \%$ del total, son cuadradas con dimensiones aproximadas de 90 x 90 metros. Dichas manzanas son las siguientes: 4, 7, 8, $12,17,18$.

- Se identifica que 02 manzanas, las cuales equivalen al 22\% del total, son triangulares/ trapezoidales. Dichas manzanas son las siguientes: 2 y 3.

- En la parcelación, con base en el Plano Catastral y el gráfico estadístico de 1949 versus el del 2019, de 09 manzanas en total, son cotejables las siguientes características:

- En el año 1949, se precisa que 03 manzanas que se encuentran frente al jirón Bolognesi, se encuentran totalmente lotizadas, cifra que equivale al 33\%; mientras que 06 manzanas se encuentran parcialmente lotizadas, lo cual equivale al $67 \%$.

- En el año 2019, se identifica que 09 manzanas que están frente al jirón, se encuentran ya totalmente lotizadas.

- Se observa que los lotes que podemos encontrar en el área de estudio son lotes regulares e irregulares.

- Es observable que los lotes están distorsionados con respecto al tipo «X», «H» $\mathrm{e}$ «Y», además que, en algunas manzanas, aún se encuentran lotes de $135 \mathrm{~m} 2$ hasta lotes de $2500 \mathrm{~m} 2$. Es decir, se comprueba que no hay una lotización regular.

Por otra parte, en la textura, de acuerdo con el Plano Catastral y el gráfico estadístico de 1949 versus el del 2019, de 09 manzanas en total, se comprueban las siguientes características: 
Figura 12. Estudio de la morfología urbana para el Jirón Bolognesi, 1949, 2019

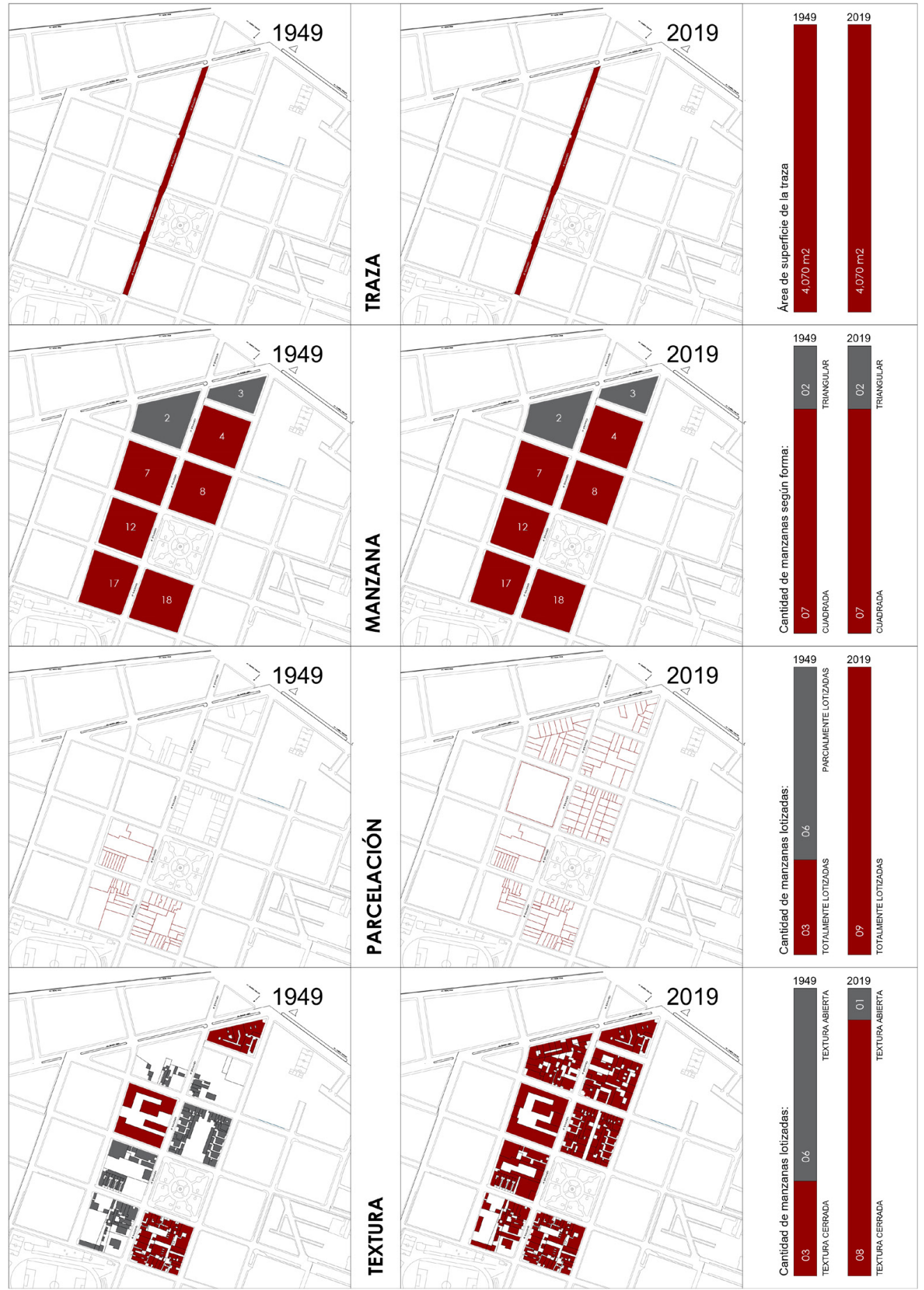

Nota. Elaboración propia, 2021 con base en: para el año 1949, de aerofotografía del Servicio Aerofotográfico Nacional; para el 2019, al trabajo de la Universidad Nacional de Ingeniería (Malpartida, La evaluación urbana y arquitectónica del Casco Histórico de Bellavista para la Declaración de Monumentos, 2016) y trabajo de campo

- En 1949, se determina que su textura en general tiende a ser abierta, es decir, en 06 manzanas 
predomina el vacío. Eso equivale a $67 \%$ del total de las manzanas que tienen textura abierta; por otra parte, 03 manzanas, lo cual equivale al 33\% del total, se observa que presentan textura cerrada, es decir, no predomina el lleno. Para el año 2019, estos porcentajes cambian.

- Se comprueba que en el año 2019, su textura en general tiende a ser cerrada, pues el $89 \%$ de ellas, es decir que, en las 08 manzanas predomina el lleno, a excepción de la plaza Isabel La Católica.

Esta es una de las calles más peculiares del distrito debido a que a través de ella se pueden observar los distintos tipos arquitectónicos mejor conservados que datan de las épocas más representativas del distrito: Republicana, de la época de Transición y Moderna, por lo cual es un espacio público que representa bastante bien los periodos de la arquitectura del distrito. Asimismo, otra de las particularidades que presenta son los árboles más antiguos de la provincia, los ficus, los cuales se localizan en la cuadra donde se ubica el emblemático Colegio América del Callao. Sin embargo, parte de estos árboles han sido talados por órdenes de la municipalidad y reemplazados por otra especie, quedando en pie pocos ejemplares los cuales merecen mayor atención y mantenimiento por las autoridades (ver figura 13). (Juma, 2019)

Figura 13. Fotografia que muestra los nuevos árboles plantados posterior a la tala de los antiguos ficus

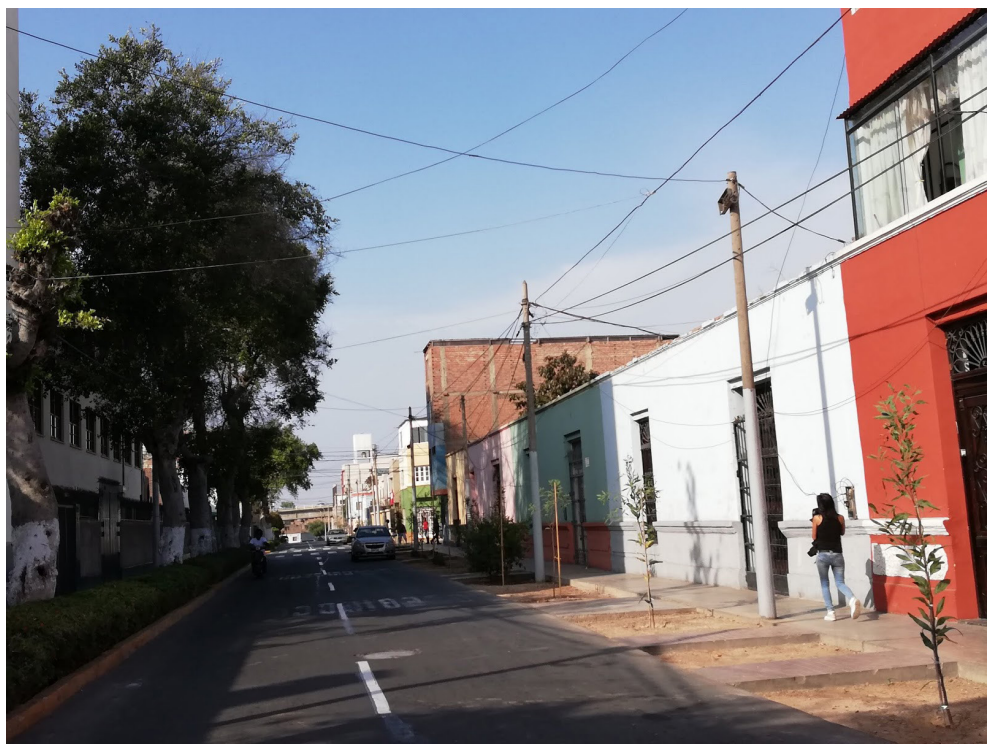

Nota. Extraido de https://www.callaocentrohistorico.com/2019/11/por-que-la-parte-antigua-de-bellavista.html. Año 2019.

Asimismo, debido al emplazamiento de este jirón con la Plaza Isabel La Católica, la vegetación histórica y su conexión con la avenida Óscar R. Benavides, anteriormente conocida como avenida Colonial y cuyo recorrido se encuentra emplazado sobre el antiguo camino prehispánico que unía Lima y Callao, hace inducir a que este Jirón Bolognesi fue, durante la época colonial, la calle principal del antiguo Centro Histórico de Bellavista.

\section{Interpretación de Resultados}

Acorde a los resultados obtenidos de cada una de las 04 variables de la morfología urbana, según la comparativa entre el Plano Catastral y el gráfico estadístico de 1949 versus el del 2019 para el Núcleo Histórico de Bellavista, la zona de estudio se mantiene intacta en cuanto a su traza y sus manzanas en ambos momentos, dicho resultado se puede explicar debido a que estas dos variables 
no se modifican en forma, superficie ni orientación. Sin embargo, en cuanto a su parcelación y su textura sí se observan diferencias considerables entre ambos años, pudiéndose comprender ello debido a la nueva subdivisión de los lotes realizada por los propietarios de los lotes de grandes áreas y debido a la construcción de nuevas viviendas.

Para el caso de estudio de la Plaza Isabel La Católica, se comprenden los siguientes resultados:

- La traza se mantiene intacta en forma, superficie y orientación en ambos años de estudio. El hallazgo de su invariabilidad se puede explicar al no haberse realizado intervenciones, renovaciones urbanas ni demoliciones en la zona que pudieran afectar su superficie o forma, situación atribuible al hecho que la zona del Núcleo Histórico donde se encuentra la plaza, se encuentra más aislada en ubicación y en transporte de los ejes comerciales más importantes del distrito, como lo es la avenida Oscar R. Benavides (ex avenida Colonial) o la avenida Elmer Faucett, la cual conecta directamente con el Aeropuerto Internacional Jorge Chávez.

- En la variable manzanas, las 09 unidades que rodean a la plaza se mantienen igual en los años 1949 y en 2019. Dicho resultado se puede explicar debido a que, al igual que para el caso de la traza, no hubieron intervenciones o renovaciones urbanas en el área, que pudieran afectar sus dimensiones. Asimismo, se puede explicar esta no distorsión de las manzanas en ambos tiempos debido a que este sector urbano se ha consolidado como un área residencial de densidad media.

- Respecto a la parcelación de las manzanas que rodean a la plaza, a comparación del año 1949, para el año 2019 ya se encuentran lotizadas en su totalidad. Este hallazgo se puede atribuir al hecho de que aquellos lotes de grandes áreas que pertenecían en el año de 1949 a un solo dueño, con el pasar de los años, se fueron subdividiendo entre sus familiares por motivos de herencia, dando como resultado una mayor cantidad de parcelas. Asimismo, se puede comprender, que por esta subdivisión de lotes se generaron parcelas irregulares.

- Por otra parte, la textura de las manzanas y lotes circundantes a la plaza los resultados demuestran que tienden a ser cerradas, lo cual se puede comprender debido a que, por lo anteriormente mencionado en la variable de parcelación, actualmente se pueden observar mayor número de lotes y construcciones, por ende, llega a predominar el lleno sobre el vacío, contrario a lo que ocurría en 1949.

Con respecto al caso de estudio del Jirón Bolognesi, se explican los siguientes resultados:

- La traza, al igual que en el caso de la plaza Isabel La Católica, ésta se mantiene intacta en forma, superficie y orientación en ambos años de estudio. El hallazgo de su invariabilidad se le atribuye el hecho de no haberse realizado intervenciones, renovaciones urbanas ni demoliciones en el jirón que pudieran afectar su superficie o forma. Asimismo, se considera el hecho de que la zona del Núcleo Histórico donde se encuentra la plaza, a pesar que llega a conectarse directamente con la avenida Oscar R. Benavides, esta se encuentra más más alejada en ubicación y en transporte de los ejes comerciales más importantes del distrito.

- En cuanto a las 09 manzanas que dan frente al jirón, éstas ya se encuentran consolidadas en los años 1949 y en 2019, dicho resultado se explica debido a que, al igual que para el caso de la traza, no hubo intervenciones o renovaciones urbanas en el área que pudieran afectar sus dimensiones. Asimismo, se le atribuye la no distorsión de las manzanas en ambos casos debido a que esta zona se ha consolidado como un área residencial de densidad media. 
- La parcelación de las manzanas que rodean al jirón, a comparación del año 1949, para el año 2019 ya se encuentran lotizadas en su totalidad. A este hallazgo se le atribiuye el hecho de que aquellos lotes de grandes áreas que pertenecían en el año de 1949 a un solo dueño, éstos, con el pasar de los años, se fueron subdividiendo entre los familiares por motivos de herencia, resultando así una mayor cantidad de parcelas y, por ende, mayores construcciones.

- Finalmente, se encuentra que la textura de las manzanas y lotes que se encuentran frente al jirón Bolognesi para el año 2019 tienden a ser cerradas, lo cual se puede comprender debido a que, por lo anteriormente mencionado en la variable de parcelación, actualmente se pueden observar mayor número de lotes y construcciones, teniendo como resultado que prime el lleno sobre el vacío. Asimismo, las ampliaciones realizadas a ciertas viviendas alteran su área generando mayor textura.

\section{Conclusiones}

Bellavista es un distrito cuyo nacimiento empieza en la época de la Colonia después del maremoto producto del sismo de 1746 que dejó al antiguo puerto del Callao totalmente destruido. Su Núcleo histórico presenta valores y características importantes que pueden llegar a formalizarse en una declaración de monumentos con la ayuda de las entidades correspondientes.

En cuanto a lo urbano, su valor radica en su traza y su emplazamiento puesto que data desde la época de la Colonia y se sigue manteniendo intacta en la mayor parte además de su continuidad de los mismos principios que se utilizaron para la creación del damero de Lima. En cuanto a su emplazamiento, al elegirse un terreno elevado sobre el nivel del mar, le brindó un paisaje marino característico único en la provincia además de conectarse con las dos vías principales de la época: el Antiguo Camino Hacia Lima por el Norte y el Camino hacia Maranga por el Sur.

Dentro de su traza se encuentran ambientes urbanos importantes como la plaza Isabel La Católica y el Jr. Bolognesi, el cual, según lo analizado, pudo ser la calle principal del Núcleo Histórico fundacional al conectar con el Antiguo Camino hacia Lima. Sin embargo, empieza a perder ese paisaje único en la provincia al perder sus característicos ficus debido a autorizaciones municipales.

- A partir del estudio ha quedado confirmado el gran valor urbano patrimonial del Núcleo Histórico del distrito de Bellavista y la viabilidad de la propuesta de declaración de la Zona Monumental de Bellavista como patrimonio cultural de la región Callao y también de la nación peruana.

- El patrimonio edificado de la Zona Monumental de Bellavista mantiene casi en su totalidad sus características generales, resaltando que la traza y las manzanas muestran evidencia desde la época Virreinal.

- En la zona del Núcleo Histórico de Bellavista, la parcelación y la textura cambia considerablemente entre los años estudiados en virtud a la nueva inversión inmobiliaria y la ausencia de políticas públicas preservasionistas de escala nacional, regional y local.

- En cuanto a la morfología urbana de ambos casos de estudio: la Plaza Isabel la Católica y el jirón Bolognesi, las similitudes que se pueden constatar se encuentran en la traza y en las manzanas, las cuales se pudo comprobar que se mantienen en forma, superficie, orientación y dimensiones concluyéndose que los motivos del por qué no hubo variación de estas dos variables en los años 1949 y 2019, se debe a la accesibilidad de la zona del área de estudio 
con respecto a avenidas principales y a los puntos comerciales más importantes del distrito de Bellavista.

- Por otra parte, para ambos casos de estudio, se encuentran diferencias en la parcelación y en la textura. Tanto para la plaza como para el jirón Bolognesi, se constata que a diferencia de 1949, para el año 2019 las parcelas ya se encuentran consolidadas en su totalidad, esto se debería a la subdivisión de lotes de las parcelas ya existentes en 1949 y a su vez, debido al proceso de densificación del Núcleo Histórico de Bellavista. Para la variable de la textura, se evidencia que tiende a ser cerrada y actualmente se está formando debido a las nuevas edificaciones que se están construyendo en el área de estudio, lo cual genera que predomine el lleno sobre el vacío.

\section{Colofón}

Debido a la ambición inmobiliaria y a la falta de proyectos de recuperación por parte de las últimas gestiones municipales para este emblemático cine en el distrito desde la década del 60, culminó finalmente en su demolición para dar paso a un nuevo edificio multifamiliar (ver figuras 14 y 15$)$.

"La destrucción de este emblemático edificio, considerado un hito en el distrito, va más allá de la misma edificación debido a que los terrenos en los que se construyeron muchas edificaciones son zonas que podrían presentar evidencia arqueológica.” (Juma, 2019)

Asimismo, existen evidencias históricas que indican que en dicho lote se encontró el que fue conocido como el Palacio de los Virreyes. El siguiente relato menciona sobre dicho lote:

"el cabildo habilitó en 1776 la casa del conde de San Javier, para ser usada en el recibimiento del nuevo virrey Manuel de Guirior. Probablemente esta sea la casa que fue usada y conocida luego como el palacio de los virreyes" (Quiroz, 2007, pág. 154).

Figura 14. Plaza Isabel La Católica en donde se puede observar uno de los últimos multifamiliares construidos y el ahora demolido Cine de Bellavista, Figura 15. Estado actual del lote donde antiguamente se localizaba el Cine de Bellavista, donde anterior a él, se ubicó el llamado Palacio de Los Virreyes. Demolido bajo la autorización de la Municipalidad del distrito
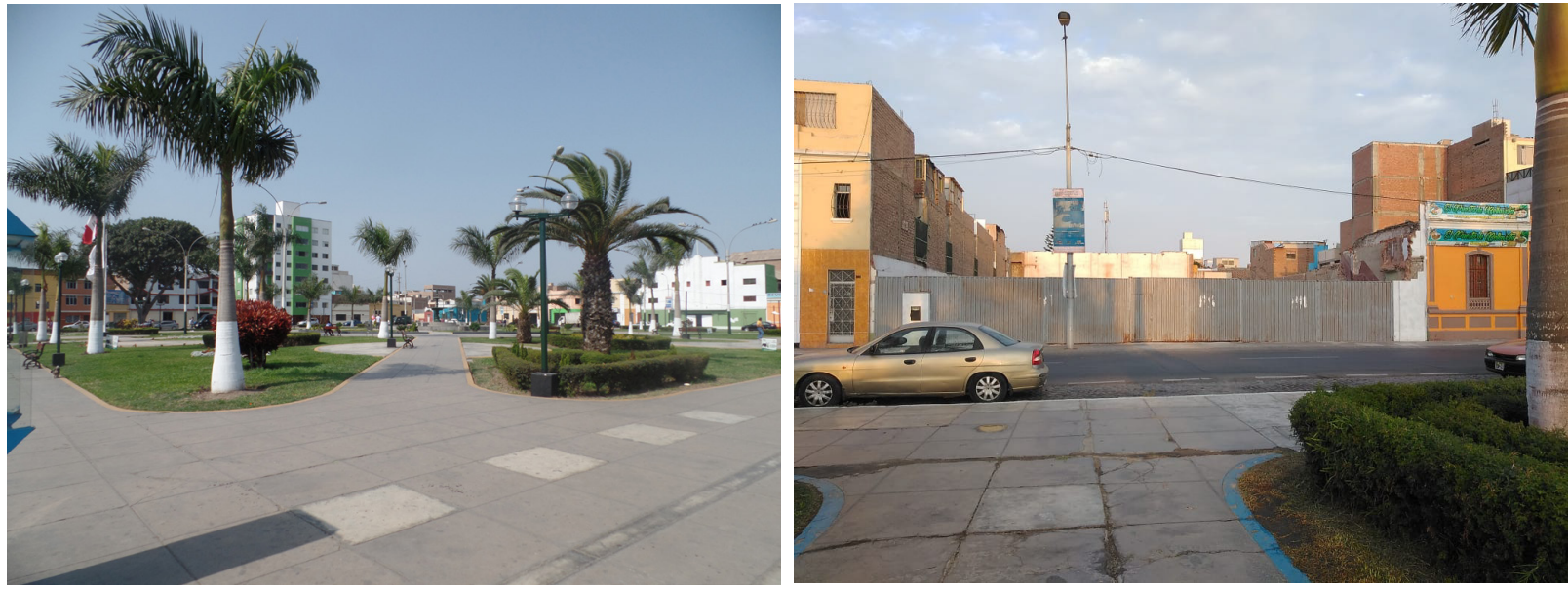

Nota. Extraidas del archivo fotográfico propio de 2016 y 2020 
A pesar que la Dirección Desconcentrada de Cultura del Callao, organismo que representa al Ministerio de Cultura del Perú en la región, a fines del año 2019 realizó esfuerzos para frenar esta demolición e intentar poner en valor dicho terreno, infortunadamente debido a temas administrativos no llegó a proceder dicha gestión culminando con la demolición del emblemático cine de Bellavista. Este infortunado acontecimiento nos hace pensar a insistir aún más para que Bellavista pueda tener la atención y el reconocimiento que se merece por parte de nuestras autoridades y así seguir evitando la pérdida de sus valores patrimoniales.

En el año 2019, para el curso de Taller de Centros Históricos de la Universidad Nacional de Ingeniería en Lima, se eligió como foco de trabajo la zona del Núcleo Histórico de Bellavista. En este taller se desarrollaron estudios urbanos y arquitectónicos con finalidad de repotenciar la zona creando diversas estrategias a nivel macro y micro acorde a la visión de la ciudad propuesta para desarrollar la rehabilitación del Centro Histórico de Bellavista (ver figura 16), incluyendo una propuesta conceptual de recuperación del Antiguo Cine, el cual en aquel momento aún no había sido demolido.

Asimismo, se realizaron previamente visitas guiadas a la zona encabezadas por los autores del presente artículo: el Dr. Arq. José Hayakawa, la Bach. Arq. Patricia Malpartida y la Arq. Kelly Jaime con el objetivo de conocer y comprender la identidad de la zona para hacer un llamado de conciencia no solo a los estudiantes y pobladores que merecen conocer su historia, sino también a las autoridades del potencial que puede tener la zona histórica de Bellavista, pues tuvo un importante rol en su historia y merece ser conocido.

Figura 16. Primeras aproximaciones para una propuesta de recuperación del Núcleo Histórico de Bellavista

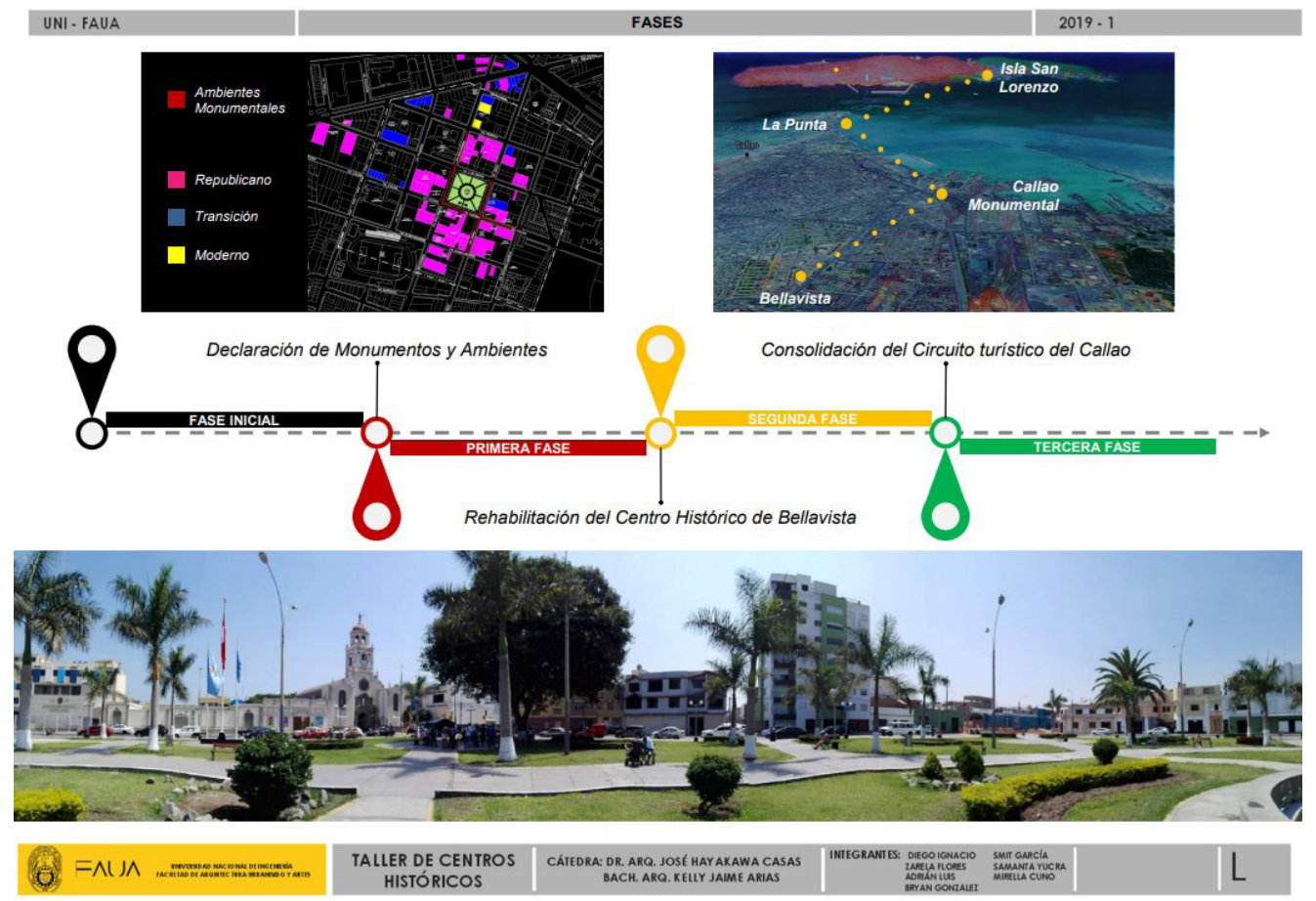

Nota. Taller de Centros Históricos de la Facultad de Arquitectura, Urbanismo y Artes de la Universidad Nacional de Ingeniería, 2019. 


\section{Referencias}

Fundación Ford - Universidad Nacional de Ingeniería. (1988). Inventario del patrimonio monumental de Lima: valles de Chillón, Rímac y Lurín. Tomo IV Época virreinal. Lima, Perú: Editorial de la Facultad de Arquitecturam Urbanismo y Artes - Universidad Nacional de Ingeniería.

Hayakawa, J. (2001). Restauración en Lima. Pasos y contrapasos (Tesis de bachillerato). Lima: Facultad de Arquitectura, Urbanismo y Artes de la Universidad Nacional de Ingeniería.

Ignacio, Diego; Flores, Zarela; Luis, Adrían; Gonzalez, Bryan; García, Smit; Yucra, Samanta; Cuno, Mirella. (2019). Informe Final del Curso Taller de Centros Históricos: Propuesta Bellavista - Callao. Lima, Perú: Facultad de Arquitectura, Urbanismo y Artes - Universidad Nacional de Ingeniería.

Juma. (2019). Callao Centro Histórico. Obtenido de El Cine Bellavista y la evidente destrucción del patrimonio cultural de un distrito chalaco. https://www.callaocentrohistorico.com/2019/10/ el-cine-bellavista-y-la-evidente.html

Malpartida, P. (2016). La evaluación urbana y arquitectónica del Casco Histórico de Bellavista para la Declaración de Monumentos. Universida Nacional de Ingeniería.

Malpartida, P. (2020). El Núcleo Histórico de Bellavista como Zona Monumental: Análisis UrbanoArquitectónico. Devenir, 7(13), 31-58. https://doi.org/10.21754/devenir.v7i13.925

Mattos-Cárdenas, L. (2004). Urbanismo Andino e Hispanoamericano. Ideas y realizaciones. Lima, Perú: Facultad de Arquitectura Urbanismo y Artes - Universidad Nacional de Ingeniería.

Municipalidad Distrital de Bellavista. (2019-2022). Distrito - Municipalidad de Bellavista. Obtenido de https://www.munibellavista.gob.pe/distrito/

Municipalidad Provincial del Callao. (2018). Municipalidad de Bellavista. http://www.munibellavista.gob.pe/wp-content/uploads/2019/09/Plano-de-Bellavista_zonificacion-2018.pdf

Quevedo, C. (2016). Criterios para la Conservación y Revalorización del Urbanismo Colonial Hispanoamericano: Estudio de caso. Devenir, 3(6), 9-30. https://doi.org/10.21754/devenir. v3i6.298

Quiroz, F. (2007). Historia del Callao: De Puerto de Lima a Provincia Constitucional. Lima, Perú: Fondo Editorial del Pedagógico San Marcos.

Ríos, M. (2014). Urbanismo Barroco en Lima Virreinal: Hacia la recuperación de la Calle de la Amargura. Devenir, 1(13), 40-58. https://doi.org/10.21754/devenir.v1i2.250

Sgroi, A. (2009). Morfología urbana: paisaje urbano. La Plata: Universidad de La Plata. Programa de investigaciones del Taller. 